\title{
Research Paper: Exploring the Therapeutic Effects of Transcranial Direct Current Stimulation on Sleep Quality \\ Among Patients Under Methadone Maintenance Treatment
}

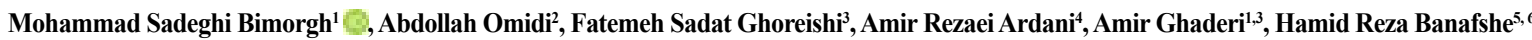 \\ 1. Department of Addiction Studies, School of Medicine, Kashan University of Medical Sciences, Kashan, Iran. \\ 2. Department of Clinical Psychology, School of Medicine, Kashan University of Medical Science, Kashan, Iran. \\ 3. Clinical Research Development Unit-Matini/Kargarnejad Hospital, Kashan University of Medical Sciences, Kashan, Iran. \\ 4. Psychiatry and Behavioral Sciences Research Center, Mashhad University of Medical Sciences, Mashhad, Iran. \\ 5. Physiology Research Center, Institute for Basic Sciences, Kashan University of Medical Sciences, Kashan, Iran. \\ 6. Department of Pharmacology, School of Medicine, Kashan University of Medical Sciences, Kashan, Iran.
}

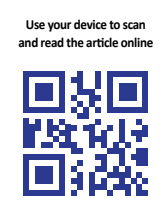

dtation: Sadeghi Bimorgh M, Omidi A, Sadat Ghoreishi F, Rezaei Ardani A, Ghaderi A, Banafshe HR. Exploring the Therapeutic Effects of Transcranial Direct Current Stimulation on Sleep Quality Among Patients Under Methadone Maintenance Treatment. International Journal of Medical Toxicology and Forensic Medicine. 2020; 10(2):29088. https://doi.org/10.32598/ijmtfm.v10i2.29088

https://doi.org/10.32598/ijmtfm.v10i2.29088

\section{(A) 08}

Article info:

Received: 18 Feb 2020

First Revision: 23 Feb 2020

Accepted: 09 Mar 2020

Published: 20 Jun 2020

Keywords:

Transcranial direct current stimulation, Methadone, Sleep quality

\section{A B STRACT}

Background: Patients under Methadone Maintenance Therapy (MMT) are susceptible to several problems, including sleep disturbances and risk of relapse. The present study aimed to assess the effect of transcranial direct current stimulation (tDCS) on sleep quality of addicts under MMT.

Methods: This clinical trial was conducted on 27 male patients who underwent maintenance methadone therapy in MMT clinics of Mashhad City, Iran. They were divided into the experimental and sham groups. The experimental group received seven 20-min sessions of tDCS every other day. In the sham group, the electrical current was delivered for a few seconds, but the electrodes were remained to the end of the session. Sleep quality was measured at baseline, during, and after the intervention by Pittsburg Sleep Quality Index (PSQI). The obtained data were analyzed by descriptive statistics such as mean and standard deviation and inferential statistics, such as $\mathrm{t}$ test, Chi-square, Mann Whitney, and Fischer exact test in SPSS v. 25.

Results: The difference between the two groups after tDCS in sleep duration was significant $(\mathrm{P}=0.04)$. In the experimental group, the total score of sleep had a reducing trend $(\mathrm{P}<0.000)$, while in the sham group, the overall score in 3 phases of evaluation had no significant change $(\mathrm{P}=0.19)$. However, the rate of inappropriate sleep quality was not significant between the two groups after the intervention $(\mathrm{P}=0.12)$.

Conclusion: This trial demonstrated the positive effect of tDCS on sleep quality in patients under MMT programs. Further studies are needed to confirm our findings.

* Corresponding Author:

Hamid Reza Banafshe, PhD.

Address: Department of Pharmacology, School of Medicine, Kashan University of Medical Sciences, Kashan, Iran.

Tel: +98 (31) 55463378

E-mail: banafshe57@hotmail.com 


\section{Introduction}

I

nternational reports revealed that opioid use has approximately $0.7 \%$ prevalence in adults. Opioids are accounted for the second form of the illicit drugs used in the world. Illegal drug use is considered a serious problem in a variety of developed and developing countries such as Iran. These forms of drug use are the main risk factors for social and public health challenges [1-3]. A wide range of therapeutic approaches could be employed to reduce illicit drug use. Among them, Methadone Maintenance Therapy (MMT) has been emerged as an effective therapeutic procedure for decreasing individual and public harms, which are linked to illicit drug use $[2,4]$.

Despite doing various practical implementation of MMT, several questions and challenges have remained unclear. Sleep problems are common among opioid abusers who were treated with MMT [5]. These problems affect their quality of life and increasing the risk of substance relapse $[6,7]$. Therefore, investigating the effective and safe methods seems necessary to relieve sleep problems among these patients.

The specific brain oscillations by applying transcranial electrical stimulation techniques to enhance sleep quality and memory processes have become an intriguing field of research [8]. Modulating brain areas, which are involved in the sleep process, can be effective in sleep dynamics and promote sleep quality $[9,10]$. Based on the conducted studies, there is a link between electrical stimulation of the specific areas of cortex and sleep quality [11].

One of these neuromodulatory techniques is transcranial direct current stimulation (tDCS). In this technique, low-intensity electric currents are applied. It is a costeffective and non-invasive technique without severe side effects, which applies to both healthy subjects and patients with neurologic symptoms [12-16]. Based on Roizenblatt et al. study [17], tDCS increases sleep efficiency via sleep modulation, and in partic-ular, modulation of primary M1 activity in fibromyalgia. Also, the evidence suggests that tDCS might affect sleep quality and neurocognition in euthymia and is useful for relapse prevention [18]. Besides, bilateral anodal tDCS stimulation for 10 sessions (20 min each, 5 per week) demonstrated potential therapeutic effects on depression level improvement and sleep quality in patients with Parkinson disease [19].

In another study, tDCS was applied during REM (rapid eye movement) sleep, with no apparent consolidation benefit for neutral declarative memories [20]. The direct effect of tDCS stimulation and the indirect impact on sleep quality may be favorable in subjects under MMT through bilateral anodal stimulation, over DLPFC (dorsolateral prefrontal cortex), premotor, and M1 areas. Also, tDCS can change the cortical excitability and increases brain excitability by altering the resting potential of cortical neural cells $[19,21]$. The safety of tDCS in adults has been well documented and confirmed, and several reported side effects were mild and transient. Most reported adverse effects include headache, and fatigue, and burning sensation and itchiness under the electrodes [22, 23].

These lines of evidence emphasize the importance of tDCS on sleep quality and mental health, suggesting that tDCS may have beneficial effects in patients under MMT programs. Also, it may have a potential impact on nursing care, functional activities, rehabilitation potential, and functional recovery. To our knowledge, data from studies investigating the effects of tDCS on promoting sleep quality in MMT patients are limited. Therefore, this study aimed to evaluate the impact of tDCS on sleep quality among patients under MMT.

\section{Materials and Methods}

\section{Trial design and participants}

This randomized, double-blinded, placebo-controlled clinical trial was registered in the Iranian Clinical Trials websiteat(http://www.irct.ir:IRCT20180604039979N1). Following the Declaration of Helsinki guideline, all patients gave their informed consent to participate in this study. This trial was conducted on 27 participants undergoing MMT. They were referred to Ibn-e-Sina Hospital in Mashhad City, Iran, from July 2018 to May 2019. A total of 27 patients were selected through convenient sampling method based on the criteria. Then, they were randomly divided into the experimental $(\mathrm{n}=14)$ and the sham $(\mathrm{n}=13)$ groups (Figure 1).

Observing the ethical considerations, the researchers provided the needed information to all patients, such as the process of treatment, probable side effects of tDCS (such as a sense of mild burning or head-ache), and duration of treatment. Then they asked patients to sign the consent form. All patients received tDCS in 7 sessions (every other day).

\section{Inclusion criteria}

The inclusion criteria were being 18-60 years old, at least having a middle educational level, receiving MMT exclusively, methadone taking for less than one year, signing a written consent form, willing to par-ticipate in the study. 


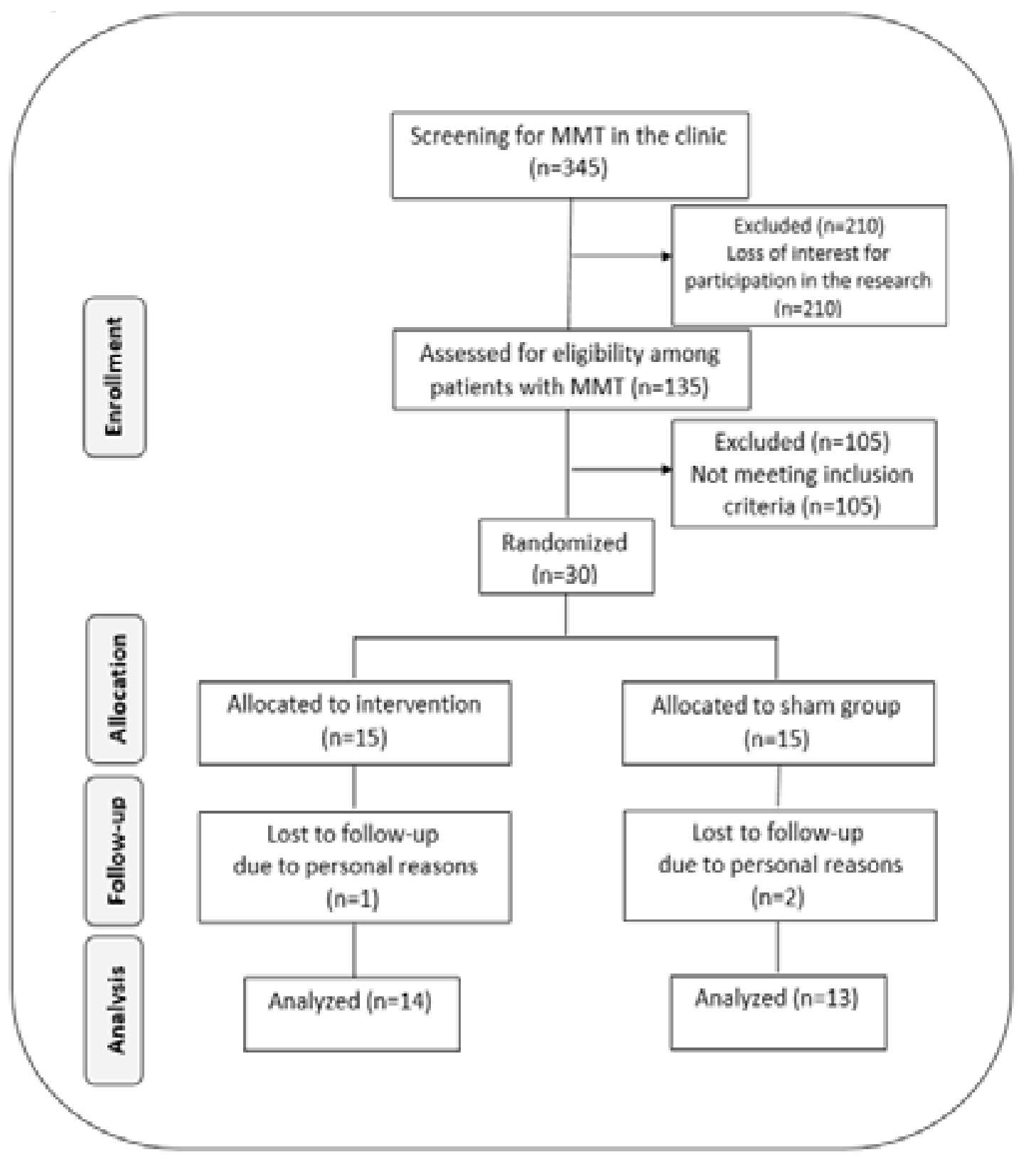

Figure 1. Flow diagram of patients' selection

\section{Exclusion criteria}

The exclusion criteria included having diabetes, neurologic disorders, history of head trauma and convulsion, metal subjects, or prosthesis near the site of stimulation, skull shunt, and heart peacemaker. Also, the patients who developed adverse effects due to stimulation were excluded from MMT.

\section{tDCS procedure}

In the experimental and sham groups, the electrodes were placed on the head over the indicated points. But the electrical stimulation was discontinued after some seconds in the sham group when the group members felt a burn in the skin, but the electrodes were remained for 20 minutes the same as the experimental group. The electrical stimulation was performed through tDCS for 20 minutes with $2 \mathrm{~mA}$ intensity and right anode and left cathode montage using carbonic electrodes on $35 \mathrm{~cm} 2$ of the scalp. The cover of the sponge was filled with saline to provide a better electrical connection between the skull and electrodes. The anode electrode (positive) was placed on the right dorsolateral prefrontal area (F4), and the cathode (negative) was placed on the left dorsolateral prefrontal area (F3) according to the 10-20 international system for EEG [22-25]. 


\section{Clinical assessments}

The clinical measurements included the demographic variables such as age, academic grade, marital status and duration, and amount of methadone use. Also, all patients fulfilled the Pittsburgh sleep quality in-dex (PSQI) in 3 phases: at baseline (at the first session before the intervention), during (at the fourth session), and at the end of the intervention (at the seventh session).

Buysse et al. developed PSQI in Pittsburgh Psychiatric Institute in 1989. The internal consistency of the questionnaire was obtained using the Cronbach $\alpha$ as 0.83 . The questionnaire has nine items in its original form, but the fifth question contains 10 sub-items, so the entire questionnaire has 19 items, which are scored based on a 4-point Likert-type scale from 0 to 3 . The questionnaire has seven subscales: subjective sleep quality, sleep latency, sleep duration, habitual sleep efficiency, sleep disturbances, use of sleeping medication, and daytime dysfunction. The interpretation of the scores is that 0 indicates a very favorable situation, 1 a relatively favorable, 2 a relatively unfavorable, and 3 very unfavorable. The total score ranges from 0 to 21 . The scores between 0 and 5 score are considered as the optimal sleep quality, and the scores between 6 and 21 are regarded as undesirable sleep quality [26].

\section{Statistical analysis}

The Kolmogorov-Smirnov test was done to determine the normality of data. The obtained data were analyzed by descriptive statistics such as mean and standard deviation and inferential statistics, including t-test, Chi-square, MannWhitney, and Fischer exact tests in SPSS.

\section{Results}

Table 1 presents the demographic variables of the patients who underwent methadone maintenance therapy. The findings related to sleep quality indexes among two groups of patients treated by tDCS and sham are presented in tables 2,3 , and 4 . The difference between the two groups after tDCS in sleep duration was significant, while in the other indexes, there were no significant differences between the two groups. Besides, the results of the inner group evalu-

Table 1. Demographic characteristics of methadone patients

\begin{tabular}{|c|c|c|c|}
\hline \multicolumn{2}{|c|}{ Variables } & Experimental Group ( $n=14)$ & Sham Group ( $n=13)$ \\
\hline \multicolumn{2}{|c|}{ Age (y) } & $37.36 \pm 7.63$ & $36.00 \pm 5.69$ \\
\hline \multirow{2}{*}{ Educational grade } & Intermediate & $10(71.4)$ & $10(76.9)$ \\
\hline & & $4(28.6)$ & $3(23.1)$ \\
\hline \multirow{3}{*}{ Marital status } & Single & $3(21.4)$ & $3(23.1)$ \\
\hline & Married & $10(71.4)$ & $8(61.5)$ \\
\hline & Divorced & $1(7.2)$ & $2(15.4)$ \\
\hline \multirow{3}{*}{ Job } & Unemployed & $9(64.3)$ & $4(30.8)$ \\
\hline & Employed & $1(7.1)$ & $0(0)$ \\
\hline & Others & $4(28.6)$ & $9(69.2)$ \\
\hline \multirow{3}{*}{ Psychiatric comorbidity } & None & $12(85.7)$ & $11(84.6)$ \\
\hline & Mood disorder & $1(7.1)$ & $0(0)$ \\
\hline & Other disorders & $1(7.1)$ & $2(15.4)$ \\
\hline \multirow{3}{*}{ Use of other drugs } & None & $12(85.7)$ & $12(92.3)$ \\
\hline & Benzodiazepine & $2(14.3)$ & $0(0)$ \\
\hline & Antidepressants & $0(0)$ & $1(7.7)$ \\
\hline \multicolumn{2}{|c|}{ Methadone dose $(\mathrm{mL})$} & $10.15 \pm 3.48$ & $10.39 \pm 4.17$ \\
\hline \multicolumn{2}{|c|}{ Duration of MMT (y) } & $8.93 \pm 2.46$ & $8.31 \pm 2.78$ \\
\hline
\end{tabular}

Data are presented as Mean \pm SD or No. (\%). 

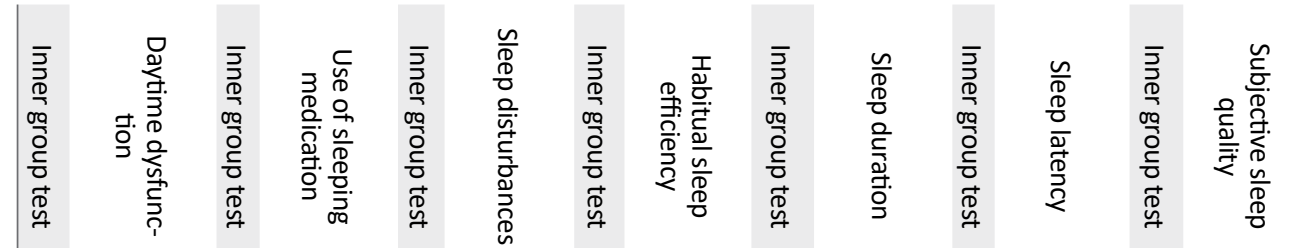

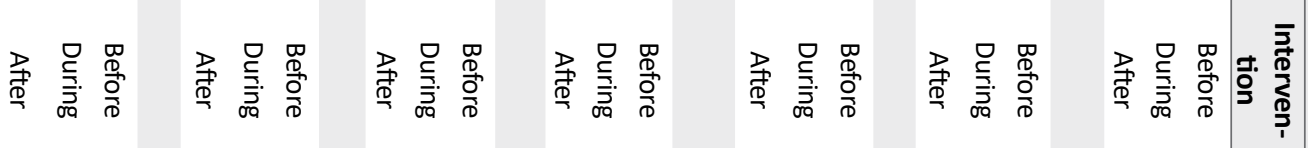

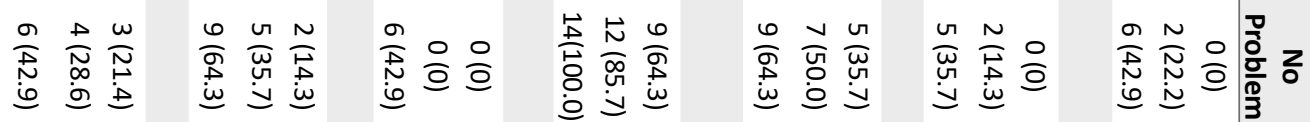

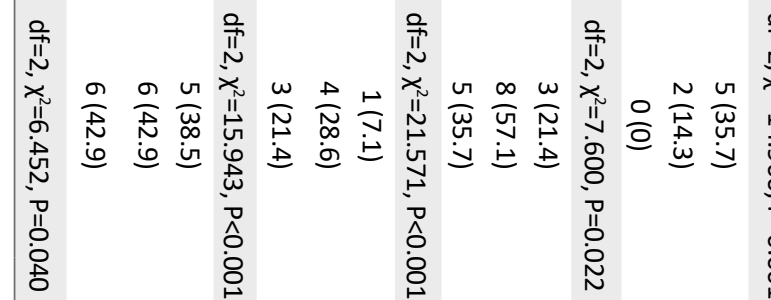

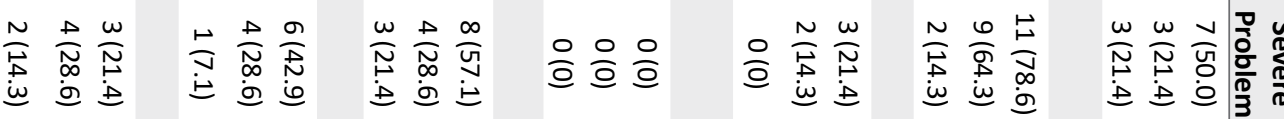

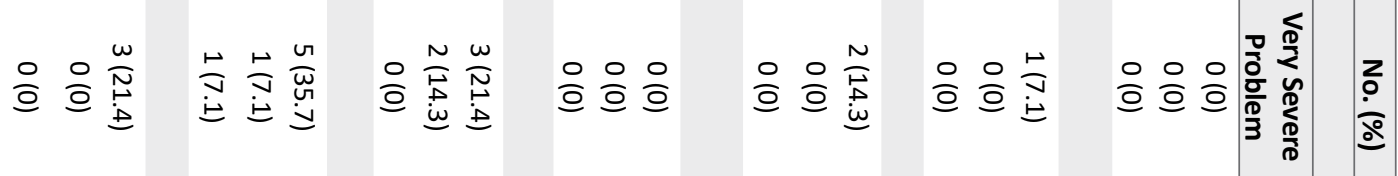

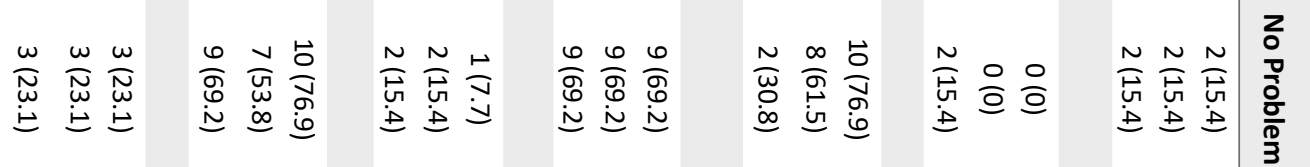

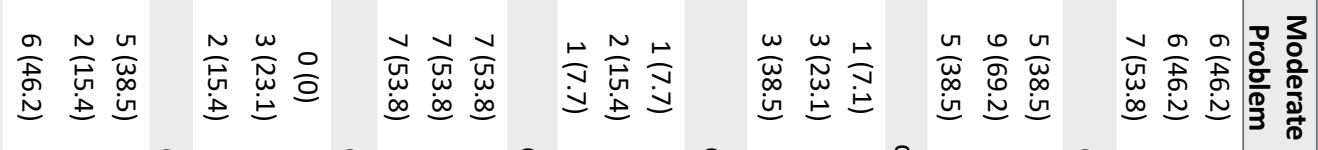

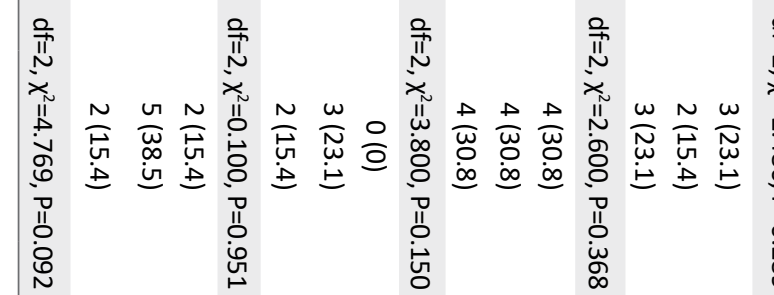

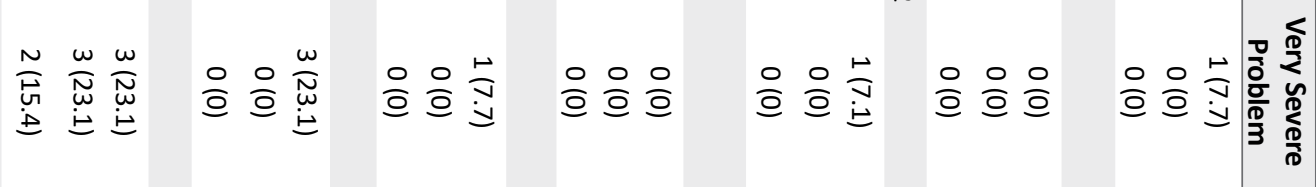

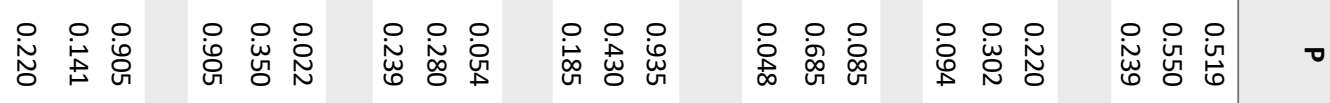


Table 3. The total score of sleep problems in the patients before and after tDCS

\begin{tabular}{|c|c|c|c|}
\hline \multirow{2}{*}{ Total Score } & \multicolumn{2}{|c|}{ Mean $\pm S D$} & \multirow{2}{*}{ Between-group Test } \\
\hline & Experimental Group & Sham Group & \\
\hline Before the intervention & $08.28 \pm 2.7$ & $7.38 \pm 4.15$ & $\begin{array}{c}\mathrm{df}=25, \mathrm{t}=0.476 \text { (independent } \\
\text { t-test), } \mathrm{P}=0.638\end{array}$ \\
\hline During the intervention & $6.93 \pm 2.76$ & $6.92 \pm 3.38$ & $\begin{array}{c}\mathrm{t}=0.005 \text { (independent } \mathrm{t} \text {-test), } \\
\mathrm{P}=0.996\end{array}$ \\
\hline After the intervention & $4.00 \pm 2.85$ & $7.00 \pm 3.27$ & $\begin{array}{c}\mathrm{z}=-2.543 \text { (Mann-Whitney test), } \\
\mathrm{P}=0.011\end{array}$ \\
\hline $\begin{array}{l}\text { Inner group test (difference between } \\
\text { before and after the intervention) }\end{array}$ & $\begin{array}{c}\mathrm{df}=13, \mathrm{t}=4.49 \text { (paired } \mathrm{t} \\
\text { test), } \mathrm{P}<0.001\end{array}$ & $\begin{array}{c}z=-0.483 \text { (Wilcoxon) } \\
P=0.629\end{array}$ & - \\
\hline $\begin{array}{l}\text { Inner group test (difference between } \\
\text { before, during and after the interven- } \\
\text { tion) }\end{array}$ & $\begin{array}{l}\mathrm{df}=2, \text { Chi-square }=16.03 \\
\text { (Friedman test), } P<0.000\end{array}$ & $\begin{array}{c}\mathrm{df}=2, \text { Chi-square }=3.282 \\
\mathrm{P}=0.194\end{array}$ & - \\
\hline
\end{tabular}

Table 4. The sleep quality in the experimental and control groups before, during, and after tDCS

\begin{tabular}{|c|c|c|c|}
\hline \multirow{2}{*}{ Sleep Quality } & \multicolumn{2}{|l|}{ No.(\%) } & \multirow{2}{*}{$\mathbf{P}$} \\
\hline & Experimental Group & Sham Group & \\
\hline $\begin{array}{l}\text { Before the intervention } \\
\text { Appropriate } \\
\text { Inappropriate }\end{array}$ & $\begin{array}{c}1(7.1) \\
13(92.9)\end{array}$ & $\begin{array}{l}4(30.8) \\
9(69.2)\end{array}$ & 0.165 (Fischer exact) \\
\hline $\begin{array}{l}\text { During the intervention } \\
\text { Appropriate } \\
\text { Inappropriate }\end{array}$ & $\begin{array}{l}6(42.8) \\
8(57.2)\end{array}$ & $\begin{array}{l}5(38.5) \\
8(61.5)\end{array}$ & $0.816($ Chi-square $=0.054, \mathrm{df}=1)$ \\
\hline $\begin{array}{l}\text { After the intervention } \\
\text { Appropriate } \\
\text { Inappropriate }\end{array}$ & $\begin{array}{c}10(71.4) \\
4(28.6)\end{array}$ & $\begin{array}{l}5(38.5) \\
8(61.5)\end{array}$ & $0.128($ Chi-square $=2.967, \mathrm{df}=1)$ \\
\hline Inner group test & $d f=2$, Cochrane $Q=13.556, P=0.001$ & $d f=2, C$ & $Q=1.000, P=0.607$ \\
\hline
\end{tabular}

ation showed that sleep quality in the experimental group was improved after tDCS in all indexes.

The results related to the total score of sleep in the experimental and sham groups are presented in Table 3. The difference between the two groups in total sleep score was significant after the intervention. In the experimental group, the total score of sleep decreased while in the sham group, the total score in 3 phases of evaluation has not significantly changed.

Table 4 presents the sleep quality between the two groups of patients before, during, and after tDCS. Based on Cochran's test, the intervention can improve sleep quality while in the sham group, sleep quality had not significantly changed during the study. During the in- vestigation, none of the participants reported the side effects of electrical stimulation.

\section{Discussion}

In this study, we evaluated the effects of tDCS on the sleep quality of the patients undergoing MMT. We found that the difference between the two groups after tDCS regarding the sleep duration was significant. In the experimental group, the total score of sleep decreased while in the sham group, the overall score has not significantly changed. Although the rate of inappropriate sleep quality was not significantly different between the two groups after the intervention.

Previous studies have demonstrated that sleep disturbances were present in opioid use disorder and MMT [27, 28] There is no study about the effect of tDCS on the sleep qual- 
ity in MMT patients, and it seems that the present study has novelty in this field. Data documenting the effects of tDCS on sleep quality in patients under MMT is limited.

Based on the available evidence, applying tDCS can improve fatigue symptoms and sleep condition among individuals with physical and mental illnesses such as fibromyalgia, Parkinson disease, and bipolar dis-order [17, 29-31]. In a systematic review, Donde and colleagues demonstrated that tDCS could enhance the quality of sleep and neurological symptoms for euthymia patients [18]. Moreover, prefronto-cerebellar tDCS could affect a variety of clinical characteristics that are associated with bipolar disorders development (i.e., neurological symptoms, sleep, and impaired neurocognition).

In this context, prefronto-cerebellar tDCS on neurological soft signs may affect neurocognitive, sensorimotor functions, sleep, and target engagement [31-33]. However, Kim et al. [34] reported that tDCS did not lead to significant changes in sleep quality in patients with diabetic polyneuropathy. In this research, 60 patients were divided into three groups (tDCS, sham, and control). The intervention conducted for five consecutive days. There were no significant differences between the three groups regarding sleep quality.

Given that prefrontal and cerebellar regions play critical roles in the sleep processes, tDCS could target and enhance sleep in a patient with euthymic via engaging the prefronto-cerebellar area [32]. These re-sults may demonstrate that high rates of sleep disturbance during remission contribute to worse outcomes and more mood relapses [35]. Besides, sleep disturbance could be related to relapse into mania or depres-sion, and enhancement in sleep can mitigate these relapses [36, 37].

Taken together, these results suggest that treating sleep disturbance with tDCS can contribute to decreasing mood relapses and treatment resistance [35]. Hence, prefronto-cerebellar tDCS can improve cognitive performance and sleep abnormalities [38]. Although there is no specific mechanism for the effect of tDCS on sleep quality, one of the reasons may be the involvement of the right and left DLPFC in sleep quality. Also, fMRI and source modeling EEG has shown that slow sleep waves are primarily associated with activity in a core set of cortical areas that are mainly located in the left and right prefrontal cortex and DLPFC [29].

Besides, an EEG study identified the cortical topography of local sleep and showed that the prefrontal cortex and DLPFC activities are associated with sleep functions
[30]. Therefore, we assume that right anodal and left cathodal tDCS over right and left DLPFC is involved in sleep regulation. More powerful randomized controlled trials are needed to clarify the effectiveness of tDCS.

The present study had some limitations, such as lack of female patients and follow-up periods, to assess the persistency of the effects. Besides, we were unable to evaluate the physical and psychiatric co-morbidities in patients under the MMT program. So, its performance is suggested in other studies. Also, long-term intervention is linked to illustrate better effects. Further studies on male and female patients with larger sample sizes and follow-ups can provide more accurate findings.

\section{Conclusion}

Our results suggest the positive effect of tDCS to improve sleep quality in the experimental group compared to the sham subjects. So, it can be applied as a safe and effective technique to relieve sleep disturb-ances among patients under MMT. Informed consent was obtained from all individual participants included in the study.

\section{Ethical Considerations}

\section{Compliance with ethical guidelines}

All procedures performed in studies involving human participants followed the ethical standards of the institutional and or national research committee and complied with the 1964 Helsinki Declaration and its later amendments or comparable ethical standards. The Ethics Committee of Kashan University of medical sciences approved the present study (IR.KAUMS.MEDNT.REC.1397.009). This research registered in the Iranian Center for Clinical Trials (Code: IRCT20180604039979N1). All patients signed written consent.

\section{Funding}

Kashan University of Medical Sciences funded the research.

\section{Author's contributions}

Design, conceptualization, statistical analysis: Mohammad Sadeghi Bimorgh and Hamid Reza Banafshe; Supervision: Hamid Reza Banafshe; Collecting data, drafting the manuscript, approve the final manuscript: All authors.

\section{Conflict of interest}

The authors declared no conflict of interest. 


\section{References}

[1] Malekinejad M, Vazirian M. Transition to injection amongst opioid users in Iran: Implications for harm reduction. Int J Drug Policy. 2012; 23(4):333-7. [DOI: 10.1016/j.drugpo.2011.09.001] [PMID]

[2] Khazaee-Pool M, Moeeni M, Ponnet K, Fallahi A, Jahangiri L5, Pashaei T. Perceived barriers to methadone maintenance treatment among Iranian opioid users. Int J Equity Health. 2018; 17(1):75. [DOI:10.1186/s12939-018-0787-z] [PMID] [PMCID]

[3] Amin-Esmaeili M, Rahimi-Movaghar A, Sharifi V, Hajebi A, Radgoodarzi R, Mojtabai R, et al. Epidemiology of illicit drug use disorders in Iran: Prevalence, correlates, comorbidity and service utilization results from the Iranian Mental Health Survey. Addiction. 2016; 111(10):1836-47. [DOI:10.1111/add.13453] [PMID]

[4] Dolan KA, Shearera J, MacDonald M, Matticka RP, Hallc W, Wodak AD. A randomised controlled trial of methadone maintenance treatment versus wait list control in an Australian prison system. Drug Alcohol Depend. 2003; 72(1):59-65. [DOI:10.1016/ S0376-8716(03)00187-X]

[5] Li DJ, Chung KS, Wu HC, Hsu CY, Yen CF. Predictors of sleep disturbance in heroin users receiving methadone maintenance therapy: A naturalistic study in Taiwan. Neuropsychiatr Dis Treat. 2018; 14:2853-9. [DOI:10.2147/NDT.S177370] [PMID] [PMCID]

[6] Kim J, Park EC, Yoo KB, Park S. The association between short or long sleep times and Quality of Life (QOL): Results of the korea national health and nutrition examination survey (KNHANES IV-V). J Clin Sleep Med. 2015; 11(6):625-34. [DOI:10.5664/ jcsm.4772] [PMID] [PMCID]

[7] Hasler BP, Smith LJ, Cousins JC, Bootzin RR. Circadian rhythms, sleep, and substance abuse. Sleep Med Rev. 2012; 16(1):67-81. [DOI:10.1016/j.smrv.2011.03.004] [PMID] [PMCID]

[8] Bueno-Lopez A, Eggert T, Dorn H, Danker-Hopfe H. Slow oscillatory transcranial direct current stimulation (so-tDCS) during slow wave sleep has no effects on declarative memory in healthy young subjects. Brain Stimul. 2019; 12(4):948-58. [DOI:10.1016/j. brs.2019.02.012] [PMID]

[9] Ladenbauer J, Külzow N, Passmann S, Antonenko D, Grittner $\mathrm{U}$, Tamm S, et al. Brain stimulation during an afternoon nap boosts slow oscillatory activity and memory consolidation in older adults. Neuroimage. 2016; 142:311-23. [DOI:10.1016/j.neuroimage.2016.06.057] [PMID]

[10] Paßmann S, Külzow N, Ladenbauer J, Antonenko D, Grittner $\mathrm{U}$, Tamm S, et al. Boosting slow oscillatory activity using tdcs during early nocturnal slow wave sleep does not improve memory consolidation in healthy older adults. Brain Stimul. 2016; 9(5):730-9. [DOI:10.1016/j.brs.2016.04.016] [PMID]

[11] Reato D, Gasca F, Datta A, Bikson M, Marshall L, Parra LC. Transcranial electrical stimulation accelerates human sleep homeostasis. PLoS Comput Biol. 2013; 9(2):e1002898. [DOI:10.1371/ journal.pcbi.1002898] [PMID] [PMCID]

[12] Giordano J, Bikson M, Kappenman ES, Clark VP, Coslett HB Hamblin MR, et al. Mechanisms and effects of transcranial direct current stimulation. Dose Response. 2017; 15(1):1559325816685467. [DOI:10.1177/1559325816685467] [PMID] [PMCID]

[13] Krone L, Frase L, Piosczyk H, Selhausen P, Zittel S, Jahn F, et al Top-down control of arousal and sleep: Fundamentals and clini- cal implications. Sleep Med Rev. 2017; 31:17-24. [DOI:10.1016/j. smrv.2015.12.005] [PMID]

[14] Sheng J, Xie C, Fan DQ, Lei X, Yu J. High definition-transcranial direct current stimulation changes older adults' subjective sleep and corresponding resting-state functional connectivity. Int J Psychophysiol. 2018; 129:1-8. [DOI:10.1016/j. ijpsycho.2018.05.002] [PMID]

[15] Schlaug G, Renga V, Nair D. Transcranial direct current stimulation in stroke recovery. Arch Neurol. 2008; 65(12):1571-6. [DOI:10.1001/archneur.65.12.1571] [PMID] [PMCID]

[16] Annarumma L, D’Atri A, Alfonsi V, De Gennaro L. The efficacy of transcranial current stimulation techniques to modulate resting-state EEG, to affect vigilance and to promote sleepiness. Brain sciences. 2018; 8(7):E137. [DOI:10.3390/brainsci8070137] [PMID] [PMCID]

[17] Roizenblatt S, Fregni F, Gimenez R, Wetzel T, Rigonatti $\mathrm{SP}$, Tufik $\mathrm{S}$, et al. Site-specific effects of transcranial direct current stimulation on sleep and pain in fibromyalgia: A randomized, sham-controlled study. Pain Pract. 2007; 7(4):297-306. [DOI:10.1111/j.1533-2500.2007.00152.x] [PMID]

[18] Dondé C, Neufeld NH, Geoffroy PA. The impact of transcranial Direct Current Stimulation (tDCS) on bipolar depression, mania, and euthymia: A systematic review of preliminary data. Psychiatr Q. 2018; 89(4):855-67. [DOI:10.1007/s11126-018-9584-5] [PMID]

[19] Hadoush H, Al-Sharman A, Khalil H, Banihani SA, Al-Jarrah M. Sleep quality, depression, and quality of life after bilateral anodal transcranial direct current stimulation in patients with parkinson's disease. Med Sci Monit Basic Res. 2018; 24:198-205. [DOI:10.12659/MSMBR.911411] [PMID] [PMCID]

[20] Marshall L, Kirov R, Brade J, Mölle M, Born J. Transcranial electrical currents to probe EEG brain rhythms and memory consolidation during sleep in humans. PLoS One. 2011; 6(2):e16905. [DOI:10.1371/journal.pone.0016905] [PMID] [PMCID]

[21] Brunoni AR, Nitsche MA, Bolognini N, Bikson M, Wagner $\mathrm{T}$, Merabet $\mathrm{L}$, et al. Clinical research with transcranial direct current stimulation (tDCS): Challenges and future directions. Brain Stimul. 2012; 5(3):175-95. [DOI:10.1016/j. brs.2011.03.002] [PMID] [PMCID]

[22] Fertonani A, Ferrari C, Miniussi C. What do you feel if I apply transcranial electric stimulation? Safety, sensations and secondary induced effects. Clin Neurophysiol. 2015; 126(11):2181-8. [DOI:10.1016/j.clinph.2015.03.015] [PMID]

[23] Poreisz C, Boros K, Antal A, Paulus W. Safety aspects of transcranial direct current stimulation concerning healthy subjects and patients. Brain Res Bull. 2007; 72(4-6):208-14. [DOI:10.1016/j. brainresbull.2007.01.004] [PMID]

[24] Frase L, Piosczyk H, Zittel S, Jahn F, Selhausen P, Krone L, et al., Modulation of total sleep time by transcranial direct current stimulation (tDCS). Neuropsychopharmacology. 2016; 41(10):2577. [DOI:10.1038/npp.2016.65] [PMID] [PMCID]

[25] Lefaucheur JP, Antal A, Ayache SS, Benninger DH, Brunelin J, Cogiamanian F, et al. Evidence-based guidelines on the therapeutic use of transcranial direct current stimulation (tDCS). Clin Neurophysiol. 2017; 128(1):56-92. [DOI:10.1016/j. clinph.2016.10.087] [PMID] 
[26] Buysse, D.J., et al., The Pittsburgh Sleep Quality Index: A new instrument for psychiatric practice and research. Psychiatry Res. 1989; 28(2):193-213. [DOI:10.1016/0165-1781(89)90047-4]

[27] Stein MD, Herman DS, Bishop S, Lassor JA, Weinstock M, Anthony J, et al. Sleep disturbances among methadone maintained patients. J Subst Abuse Treat. 2004; 26(3):175-80. [DOI:10.1016/ S0740-5472(03)00191-0]

[28] Dimsdale JE, Norman D, DeJardin D, Wallace MS. The effect of opioids on sleep architecture. J Clin Sleep Med. 2007; 3(1):33-6. https://www.ncbi.nlm.nih.gov/pubmed/17557450

[29] Murphy M, Riedner BA, Huber R, Massimini M, Ferrarelli F, Tononi G. Source modeling sleep slow waves. Proc Natl Acad Sci USA. 2009; 106(5):1608-13. [DOI:10.1073/pnas.0807933106] [PMID] [PMCID]

[30] Murphy M, Huber R, Esser S, Riedner BA, Massimini M, Ferrarelli $\mathrm{F}$, et al. The cortical topography of local sleep. Curr Top Med Chem. 2011; 11(19):2438-46. [DOI:10.2174/156802611797470 303] [PMID] [PMCID]

[31] Minichino A, Bersani FS, Spagnoli F, Corrado A, De Michele F, Calò WK, et al. Prefronto-cerebellar transcranial direct current stimulation improves sleep quality in euthymic bipolar patients: A brief report. Behav Neurol. 2014; 2014:876521. [DOI:10.1155/2014/876521] [PMID] [PMCID]

[32] Minichino A, Bersani FS, Bernabei L, Spagnoli F, Vergnani L, Corrado A, et al. Prefronto-cerebellar transcranial direct current stimulation improves visuospatial memory, executive functions, and neurological soft signs in patients with euthymic bipolar disorder. Neuropsychiatr Dis Treat. 2015; 11:2265-70. [DOI:10.2147/ NDT.S79108] [PMID] [PMCID]

[33] Benson BE, Willis MW, Ketter TA, Speer A, Kimbrell TA, George MS, et al. Interregional cerebral metabolic associativity during a continuous performance task (Part II) : Differential alterations in bipolar and unipolar disorders. Psychiatry Res. 2008; 164(1):30-47. [DOI:10.1016/j.pscychresns.2007.12.016] [PMID]

[34] Kim YJ, Ku J, Kim HJ, Im DJ, Lee HS, Han KA, et al. Randomized, sham controlled trial of transcranial direct current stimulation for painful diabetic polyneuropathy. Ann Rehabil Med. 2013; 37(6):766-76. [DOI:10.5535/arm.2013.37.6.766]

[35] Geoffroy PA, Scott J, Boudebesse C, Lajnef M, Henry C, Leboyer M, et al. Sleep in patients with remitted bipolar disorders: A meta-analysis of actigraphy studies. Acta Psychiatr Scand. 2015; 131(2):89-99. [DOI:10.1111/acps.12367] [PMID]

[36] Kennedy SH, Javanmard M, Vaccarino FJ. A review of functional neuroimaging in mood disorders: Positron emission tomography and depression. Can J Psychiatry. 1997; 42(5):467-75. [DOI:10.1177/070674379704200502] [PMID]

[37] Praharaj SK, Ram D, Arora M. Efficacy of high frequency (rapid) suprathreshold repetitive transcranial magnetic stimulation of right prefrontal cortex in bipolar mania: A randomized sham controlled study. J Affect Disord. 2009; 117(3):146-50. [DOI:10.1016/j.jad.2008.12.020] [PMID]

[38] Samalin L, Boyer L, Murru A, Pacchiarotti I, Reinares M, Bonnin CM, et al. Residual depressive symptoms, sleep disturbance and perceived cognitive impairment as determinants of functioning in patients with bipolar disorder. J Affect Disord. 2017; 210:280-6. [DOI:10.1016/j.jad.2016.12.054] [PMID] 
This Page Intentionally Left Blank 